\title{
Estimation of wavy honeycombs' compression performance via a machine learning algorithm
}

\author{
Alparslan Solak ${ }^{a *}$ (D) , Birgül Aşçıŏlu Temiztaşa (D), Berna Bolat ${ }^{a}$ \\ ${ }^{a}$ Department of Mechanical Engineering, Yildiz Technical University, 34349 Besiktas, Istanbul, Turkey. Email: asolak@yildiz.edu.tr, \\ birgul@yildiz.edu.tr, balpan@yildiz.edu.tr
}

* Corresponding author

https://doi.org/10.1590/1679-78256761

\begin{abstract}
In this study, the wavy honeycomb's initial peak crushing force (IPCF) and energy absorption (EA) were estimated using the decision tree algorithm. First, using experimental results, Ls-Dyna models of honeycombs were verified. In this way, the stress-strain curves and shapes were compatible. Secondly, the effect of parameters was examined. Waves contribute significantly to values. In particular, for honeycombs with the same geometric properties, when the wavenumber is 3 , the IPCF and specific energy absorption (SEA) values increase by $121.59 \%$ and $75.08 \%$, respectively. In addition, when the wave amplitude is $0.15 \mathrm{~mm}$, IPCF and SEA increase by $60.89 \%$ and $71.3 \%$, respectively. Afterward, using the full factorial, a data set with various parameter values was prepared. The parameters (inputs) and values (outputs) in the data set were used to train and verify the decision tree algorithm using Python. Finally, new data was introduced into the algorithm, and values were estimated. Errors ranged from $0.17 \%$ to $14.65 \%$ between Ls-Dyna and the algorithm results. These findings show that machine learning is suitable for wavy honeycombs.
\end{abstract}

\section{Keywords}

Decision tree algorithm, Compression behavior, Ls-Dyna, Python, Wavy honeycomb

\section{Graphical Abstract}
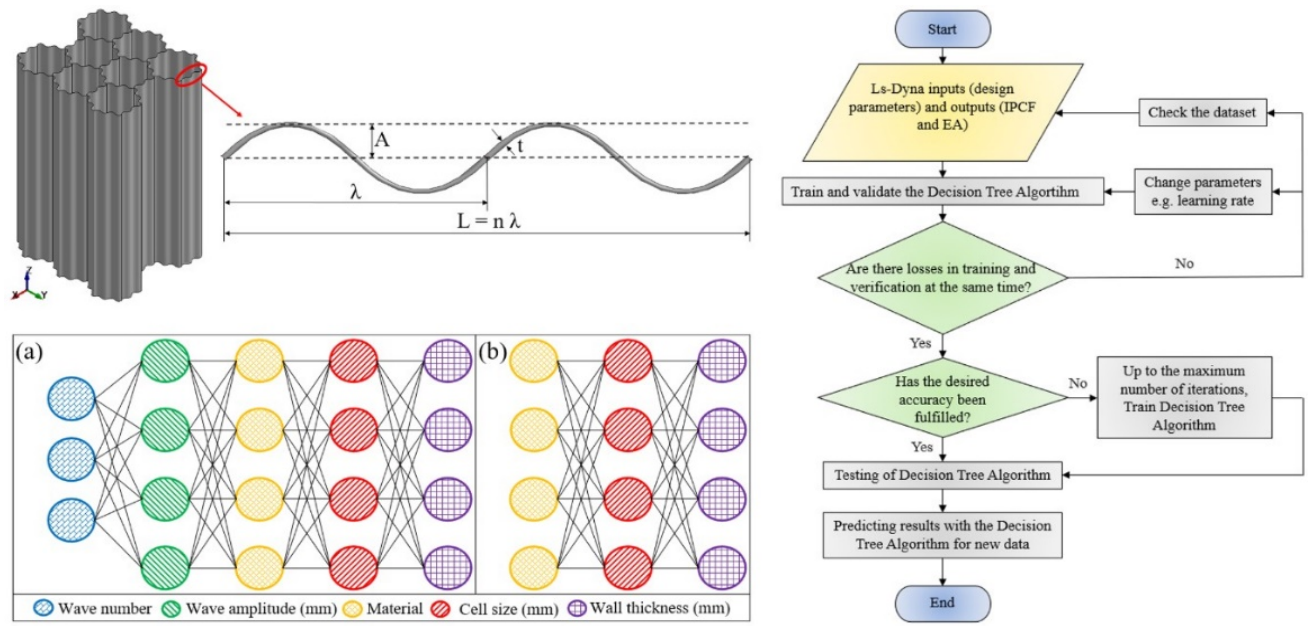

Received September 29, 2021. In revised form October 05, 2021. Accepted October 05, 2021. Available online October 06, 2021. https://doi.org/10.1590/1679-78256761

(c) Latin American Journal of Solids and Structures. ISSN 1679-7825. Copyright @ 2021. This is an Open Access article distributed under the terms of the Creative Commons Attribution License, which permits unrestricted use, distribution, and reproduction in any medium, provided the original work is properly cited. 


\section{INTRODUCTION}

Due to their high strength and low weight, honeycombs are used in many fields, especially in the aviation industry. For instance, a Boeing 747 aircraft has 4000 square meters of honeycomb (Bitzer, 1997). Energy absorption is another capability of honeycombs. Many researchers are interested in the superior mechanical properties of honeycombs. For example, the materials, cell structures, and normal tests of honeycomb structures were examined by Bitzer (1997). The mechanical properties of honeycombs, sandwich panel designs, and systems of energy absorption were mentioned in this study. Khan et al. (2012) investigated honeycombs' out-of-plane compression behavior. Crush responses were analyzed using the digital image correlation method. The effect of the impact resistance parameters of aluminum honeycombs on IPCF and SEA was investigated by Meran et al. (2014) These parameters were cell wall thickness, cell size, and cell expanding angle. In addition, to validate finite element models, experimental measurements and theoretical equations were used. Roy et al. (2014) investigated the mechanical properties of Nomex ${ }^{\circledR}$ paper and phenolic resin, which are components of the Nomex ${ }^{\circledR}$ honeycomb. Double wall thickness was adapted to approximate experimental results in the finite element model. The compression behavior of Nomex ${ }^{\circledR}$ honeycombs and carbon fiber foldcore structures was investigated by Heimbs (2009). For parametric study and optimization, the virtual test method was used. This decreased time consumption and the number of costly tests of prototypes. Moreover, the effects on mechanical properties of mesh size, material, and cell geometry were investigated. The numerical modeling of Nomex ${ }^{\circledR}$ honeycombs made of T-412 was studied by Seemann and Krause (2017). Four finite element approaches were compared with the data obtained from the experimental results. Because it fits well with experimental results, the single layer orthotropic approach has been recommended.

Inspiring by biological creatures, researchers tried to improve the mechanical performance of hexagonal honeycombs. The main objective of these studies is the versatile optimization of honeycombs' IPCF and SEA. For example, $\mathrm{Ha}$ et al. proposed a honeycomb based on waves in the woodpecker's beak microstructure (2019). To verify the finite element model of wavy honeycomb, an experimental compression test of hexagonal honeycomb was used. In order to investigate the effects of parameters such as cell wall thickness, wave number, and wave amplitude on SEA, a parametric study was conducted. These values increased by $63.7 \%$ and $125 \%$, respectively, compared to regular hexagonal honeycombs. Jiang et al. (2020) suggested a new coconut palm inspired auxetic honeycomb. The construction of this structure is based on the idea that the cells are intertwined from large to small. The crushing behavior of the reentrant honeycomb structure and deformation modes were investigated. The plateau stress and SEA of these structures are higher than in hexagonal honeycombs. Zhang et al. (2016) imitated grass stems to study hierarchical honeycombs. These structures, unlike hexagonal honeycombs, have smaller honeycombs at six corners. The hierarchical honeycomb's 2 nd order is obtained by adding six honeycombs to the corners of these small honeycombs. Additionally, to raise the crushing strength in the out-of-plane direction, a parametric study was carried out depending on material distribution. A hierarchical honeycomb structure inspired by the spider web was proposed by He et al. (2020). This structure is established by gradually placing smaller honeycombs in the center of the original honeycomb. To verify the finite element model, theoretical and experimental studies were conducted. There has been a rise in the SEA, but the IPCF rise is limited. Inspired by pomelo peel, which have a specific microstructure, Zhang et al. (2019) studied hierarchical honeycombs. This structure is established by placing seven small honeycombs of the same size into the large honeycomb. The energy absorption capacity and crushing strength were examined in this study by combining analytical and numerical approaches. The values of SEA and plateau compression rose 1.5 and 2.5 times, respectively. As a consequence of the changes in the design parameters of the honeycomb for the compression test, three deformation modes and two localized bands were observed.

A decision tree algorithm can predict the result with a low error rate and computation cost (Maimon and Rokach, 2014). Therefore, it has been used in many studies in the literature. For instance, Qi et al. (2019) used a decision tree to correlate carbon fiber variables and composite parameters. Using the finite element method (FEM) for the data to be defined in machine learning, single and multilayer models of carbon fiber and the representative volume element were established. For the decision tree, four mechanical properties of carbon fiber were analyzed. For the accuracy of the model, a validation set was used. A multipurpose optimization study for a composite cylinder under axial compression load was conducted by Wagner et al. (2019) Maximum buckling load and minimum defect sensitivity were the targets of this research, in which a decision tree approach was used. In future modern launch vehicles, this study might be the basis for modeling sandwich structures. Using the decision tree, García et al. (2015) studied the mechanical behavior of compressed cork. Input parameters were defined as the density, number of pores, and test direction. The velocity of recovery and Young's modulus were estimated.

When the academic studies carried out so far were examined, it was seen that by adding the wave structure to the hexagonal honeycombs, performance was enhanced. In these studies, a small data set and only aluminum material were 
used to improve the compression performance of wavy honeycombs. Thus, attempts have been made to determine the effects of design parameters on compression performance in a narrow scope. To bridge this gap, the effects of wavy honeycombs on compression performance were investigated by creating a large data set in this study. For this aim, Nomex ${ }^{\circledR}$, glass fiber, and carbon fiber materials were used in addition to aluminum to examine the effect of parameters in a wider scope. Moreover, compression analyses were diversified through the use of 3 different wave numbers and 4 different wave amplitudes. Finite element honeycomb models were validated with stress-strain curves obtained from experimental tests. When the highest strength values are compared, the error rates are $7.47 \%$ and $6.26 \%$, respectively. Additionally, the deformation patterns of the experimental and numerical results are similar when compared. Thus, it has been shown that these results are acceptable and that these models can be used for wavy honeycombs. The basic design parameters examined are material, cell size, cell wall thickness, wave amplitude, and wave number. To understand the effect of the parameters and establish the estimation algorithm, 832 models with different parametric values were prepared using the full factorial method. The correlation matrix was established to examine the effect of design parameters on IPCF and EA. The decision tree algorithm was trained and validated using input values (design parameters) and outcome values (IPCF and EA) to evaluate large numbers of data. To determine the predictive success rate of the algorithm, the results of 11 analyses, which were not solved in Ls-Dyna before, were estimated at error rates of up to $15 \%$.

\section{VALIDATION OF LS-DYNA MODELS}

In this section, hexagonal honeycombs modeled using Ls-Dyna were validated by experimental tests. To examine the effect of the material on mechanical performance, four materials (aluminum, Nomex ${ }^{\circledR}$, carbon fiber, and glass fiber) were used (Meran et al., 2014, Heimbs, 2009, Zhou et al., 2020, Soutis et al., 2011). Aluminum is an isotropic material, while other materials are composites. For this reason, two different materials, one isotropic and the other composite, need to be verified for hexagonal honeycombs. As a result, aluminum and Nomex ${ }^{\circledR}$ materials were selected for validation of the simulation. To examine the mechanical performance of the wavy honeycombs, IPCF, SEA, and EA are employed. IPCF: During the crushing of a structure, it is expressed as the peak force in the elastic region. SEA is called per unit mass absorbed energy and can be expressed as follows:

$S E A=E A / m$

In this formula, $\mathrm{m}$ is the wavy honeycomb's mass. Energy absorption is the ability of wavy honeycomb to dissipate breaking energy by plastic deformation during compression and can be expressed as follows:

$E A=\int_{0}^{l} F(x) d x$

In this expression, $F(x)$ is a function of the distance $x$, which is the rigid wall's position expression, and I is the wavy honeycomb's compression length. The wavy honeycombs were $80 \%$ (12 $\mathrm{mm}$ ) compressed.

\subsection{Validation of aluminum honeycomb}

The hexagonal honeycomb used in the experiments (Meran et al., 2014) has a cell size of $3.175 \mathrm{~mm}$, a height of 20 $\mathrm{mm}$, a cell wall thickness of $0.025 \mathrm{~mm}$, a cross-sectional area of $900 \mathrm{~mm}^{2}$, and is comprised of aluminum material 5052 (Table 1).

Table 1 Mechanical properties of aluminum 5052.

\begin{tabular}{cccc}
\hline Parameter & Symbol & Unit & Value \\
\hline Mass density & $\mathrm{RO}$ & $\mathrm{kg} /\left(\mathrm{m}^{3}\right)$ & 2685 \\
Young's modulus & $\mathrm{E}$ & $\mathrm{GPa}$ & 70.32 \\
Poisson's ratio & $\mathrm{PR}$ & - & 0.33 \\
Strength coefficient & $\mathrm{K}$ & - & 0.3644 \\
Hardening exponent & $\mathrm{N}$ & - & 0.099842 \\
\hline
\end{tabular}


For plastic deformation, the material model MAT18 (Power_Low_Plasticity) was selected. Shell elements of the Belytschko-Tsay (Heimbs, 2009) with a mesh size of $0.114 \mathrm{~mm}$ were used. The honeycomb was modeled as eight cells (Seemann and Krause, 2014) for a shorter analysis time (Figure 1).

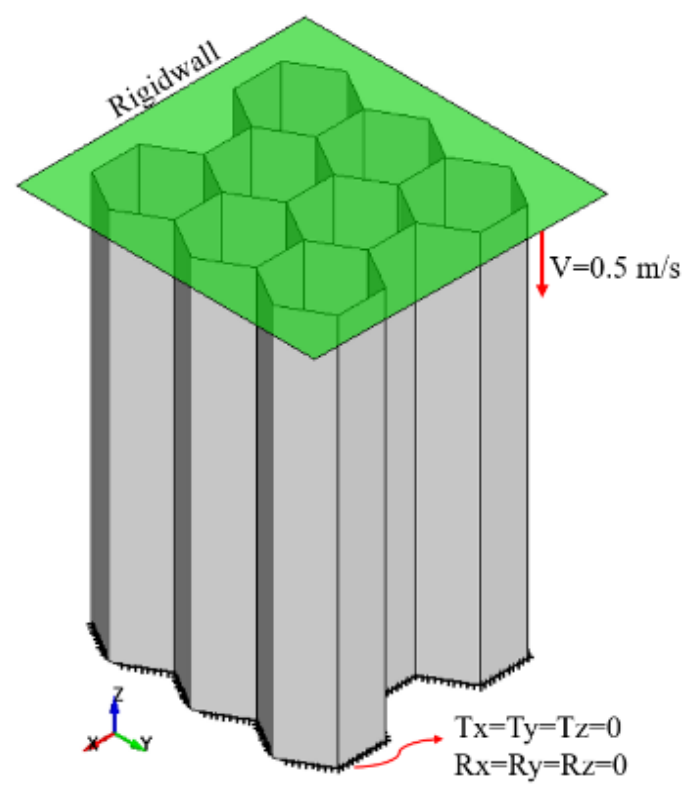

Figure 1 Aluminum honeycomb model and rigidwall.

For general contact in Ls-Dyna, Automatic_Single_Surface (Hou et al., 2015) was defined. The coefficient of friction was set to 0.2 (Soutis et al., 2011). The lower nodes' six degrees of freedom were constrained. Moreover, the joints at the top were allowed to move only in the out-of-plane direction. The rigid wall model (Zhang et al., 2013) compressed the honeycomb in the out-of-plane direction with a constant velocity of $0.5 \mathrm{~m} / \mathrm{s}$. Figure 2 shows the stress-strain curve of the $80 \%$ (12 mm/15 mm) compressed honeycomb.

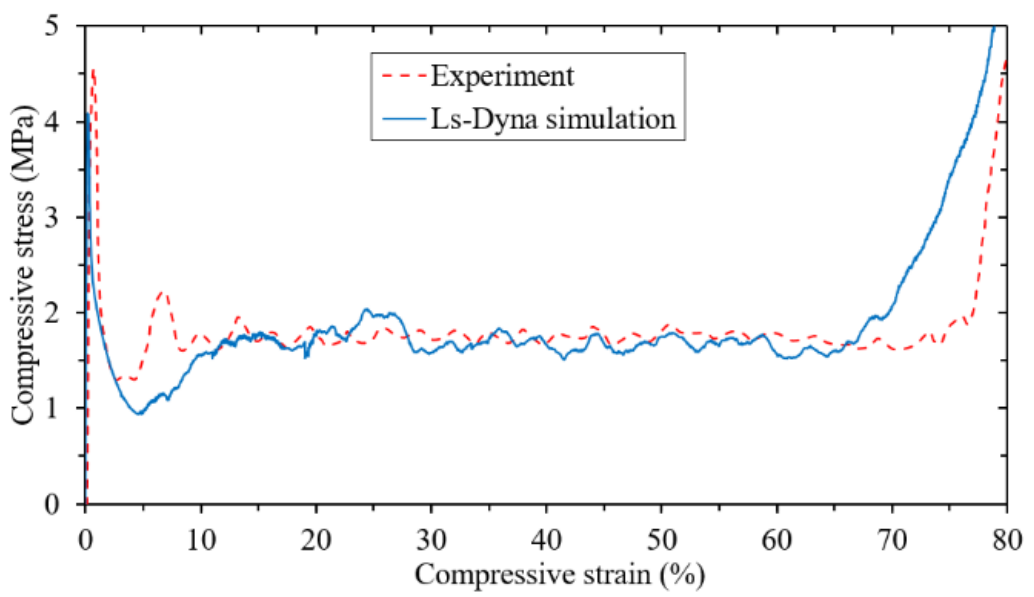

Figure 2 Aluminum honeycomb's experimental (Meran et al., 2014) and Ls-Dyna stress-strain curves.

The aluminum honeycomb is elastically compressed $(\varepsilon=0.33 \%)$ to the maximum level. The cell walls start to buckle from this point on, and plastic hinges appear. This is the plateau zone, and there is almost constant compression stress. From the point where the plateau zone ends $(\varepsilon=75 \%)$, the densification zone starts, and the stress ascends. Experimental and numerical compressive strengths are 4.55 MPa and 4.21 MPa, respectively. There is a difference of $7.47 \%$ between the strengths. Figure 3 shows images of the $80 \%$ compressed aluminum honeycombs in the Ls-Dyna and experiment. In the experimental test and the Ls-Dyna model, there are 10 plastic hinges. Furthermore, the folding shapes are similar to each other. 


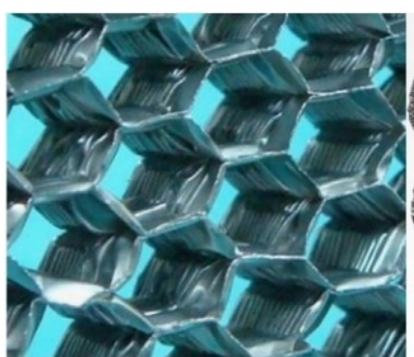

(a)

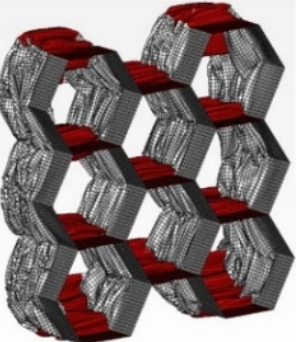

(b)

Figure 3 Deformation mode of $80 \%$ compressed aluminum honeycomb (a) experiment (Meran et al., 2014) and (b) Ls-Dyna model.

\subsection{Validation of Nomex $^{\circledR}$ (composite material) honeycomb}

To verify the composite material model, the compression behavior of the Nomex ${ }^{\circledR}$ honeycomb was examined in this section. In the experiment, the cell size, density, and height of the Nomex ${ }^{\circledR}$ honeycomb are $3.2 \mathrm{~mm}, 48 \mathrm{~kg} / \mathrm{m}^{3}$, and $15 \mathrm{~mm}$ respectively (Heimbs, 2008). The Nomex ${ }^{\circledR}$ honeycomb is produced in hexagonal form by bonding Nomex ${ }^{\circledast}$ paper. This paper is an aramid fiber impregnated with phenolic resin. The mechanical properties of this aramid paper are shown in Table 2.

Table 2 Mechanical properties of aramid paper (Seemann and Krause, 2017, Foo et al., 2007).

\begin{tabular}{|c|c|c|c|}
\hline Parameter & Symbol & Unit & Value \\
\hline Mass density & RO & $\mathrm{kg} /\left(\mathrm{m}^{3}\right)$ & 1100 \\
\hline Young's modulus - longitudinal direction & $E_{A}$ & $\mathrm{GPa}$ & 3.13 \\
\hline Young's modulus - transverse direction & $E_{B}$ & $\mathrm{GPa}$ & 0.955 \\
\hline Poisson's ratio - ba & $\mathrm{PR}_{\mathrm{BA}}$ & - & 0.2 \\
\hline Shear modulus - $a b$ & $\mathrm{G}_{\mathrm{AB}}$ & $\mathrm{GPa}$ & 1.45 \\
\hline Longitudinal compressive strength & $X_{C}$ & $\mathrm{MPa}$ & 105 \\
\hline Longitudinal tensile strength & $X_{T}$ & $\mathrm{MPa}$ & 90 \\
\hline Transverse compressive strength & $\mathrm{Y}_{\mathrm{C}}$ & $\mathrm{MPa}$ & 90 \\
\hline Transverse tensile strength & $\mathrm{Y}_{\mathrm{T}}$ & $\mathrm{MPa}$ & 60 \\
\hline Shear strength, ab plane & $\mathrm{S}_{\mathrm{c}}$ & $\mathrm{MPa}$ & 44 \\
\hline Failure criterion & CRIT & - & 55 \\
\hline
\end{tabular}

The same properties (mesh size, contact, boundary conditions) were used for the Nomex ${ }^{\circledR}$ honeycomb model as in the aluminum honeycomb model. In addition to its mechanically distinct machine direction and cross direction properties, the mechanical behavior of aramid paper is brittle. For these reasons, using the single-layer orthotropic approach (Seemann and Krause, 2017), the composite model MAT54 (Enhanced_Composite_Damage) was chosen. Figure 4 shows the stress-strain curve of the $80 \%$ compressed Nomex ${ }^{\circledR}$ honeycomb.

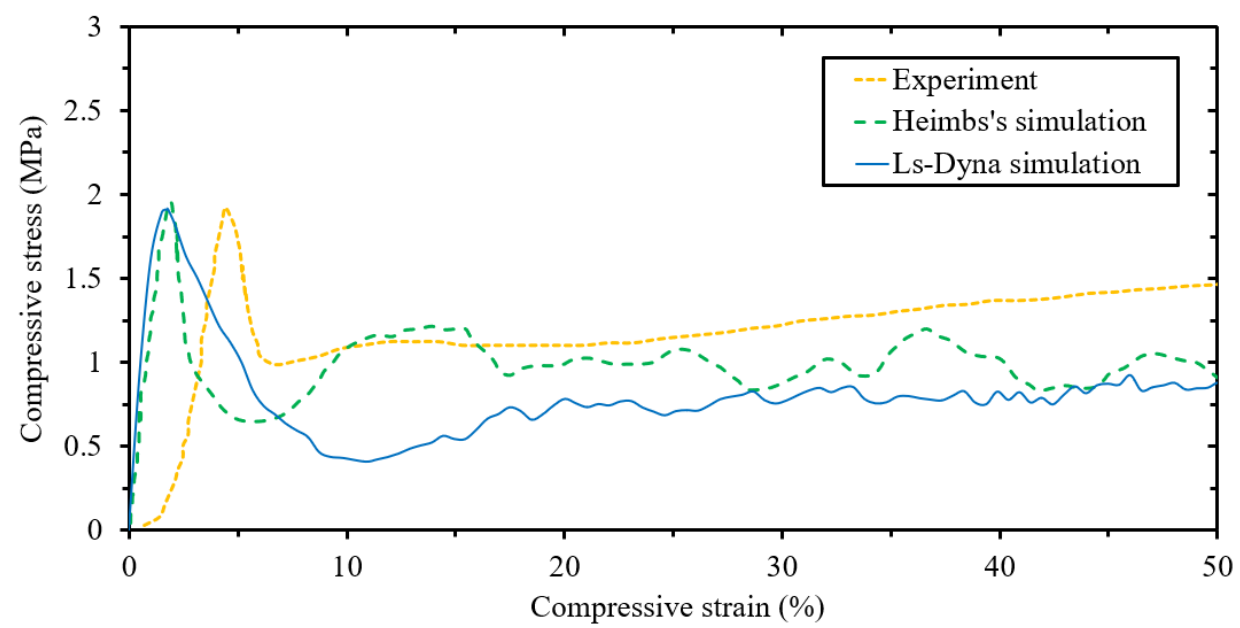

Figure 4 Nomex ${ }^{\circledR}$ honeycomb's experimental, Heimbs' simulation (2009) and Ls-Dyna simulation curves. 
Experimental and numerical compressive strengths are 1.94 MPa and $1.82 \mathrm{MPa}$, respectively. There is a difference of $6.26 \%$ between the strengths. In Figure 5, images of the $80 \%$ compressed honeycombs in the Ls-Dyna and the experiment are shown.

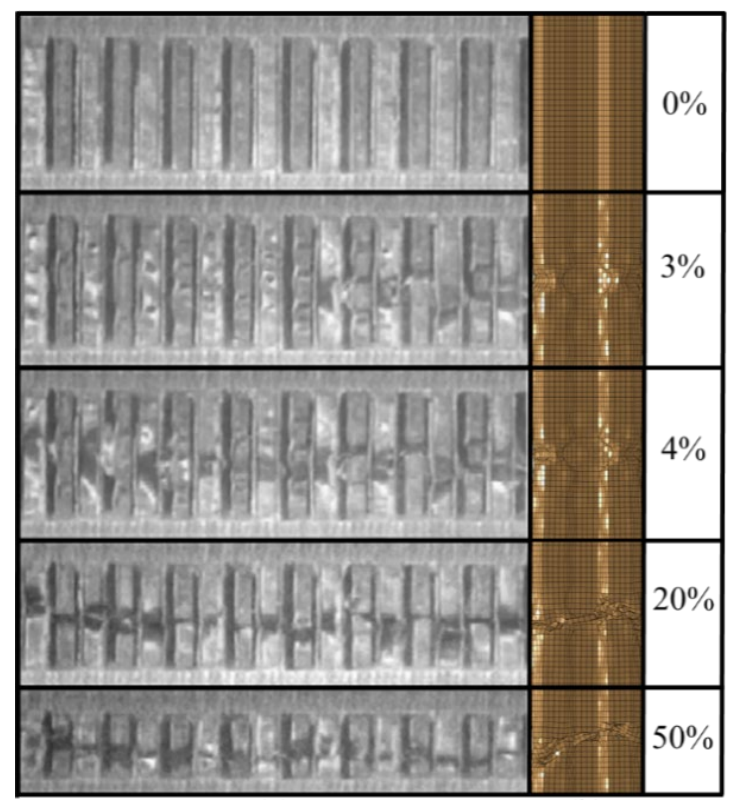

(a)

(b)

Figure 5 Nomex ${ }^{\circledR}$ honeycomb's gradual deformation modes (a) experimental test (Heimbs, 2008) and (b) Ls-Dyna model.

The honeycombs' deformation modes in Ls-Dyna and the experiment are similar. Also, the stress-strain curves of these models' are compatible. As a consequence, the mechanical properties of wavy honeycombs can be investigated using these honeycomb models.

\section{WAVY HONEYCOMBS}

The walls of the honeycombs are designed to be wavy by bioinspiration from the microstructure of the woodpecker's beak and the shape of the horseshoe (San Ha et al., 2019, Yang et al., 2018). Wavy honeycombs have higher strength and specific energy absorption capabilities than hexagonal honeycombs. In this study, cell walls were assumed to be wavy like a sinus curve. In addition, the wave number (n), wave amplitude $(A)$, wavelength $(\lambda)$, and wall thickness (t) were defined for this structure (Figure 6) (San Ha et al., 2019).

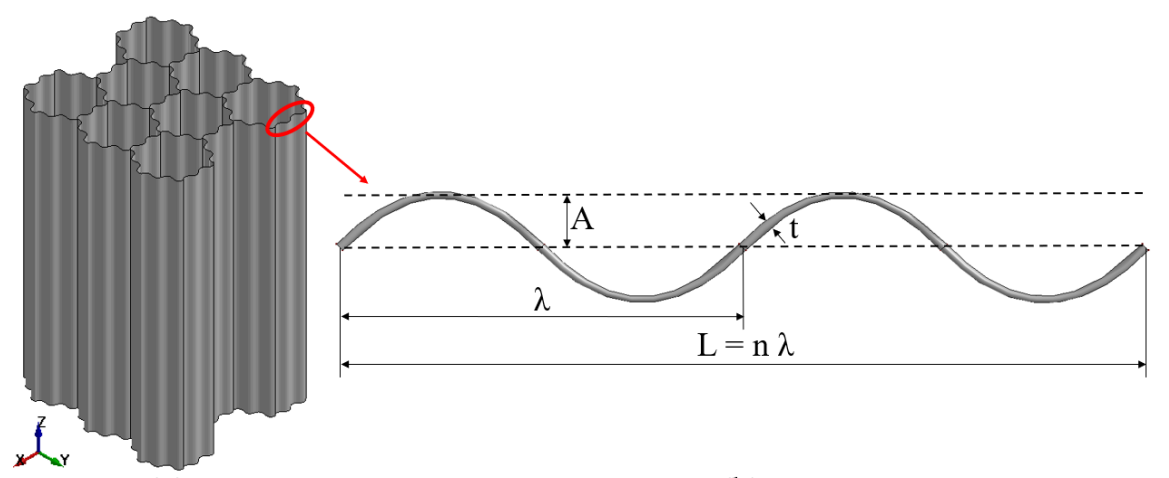

(a)

(b)

Figure 6 (a) Wavy honeycomb and (b) wavy edge.

Four wave numbers, four wave amplitudes, four materials, four cell sizes, and four wall thicknesses were considered in this study to investigate the effects of design parameters on IPCF and SEA (Table 3). 
Table 3 Design parameters.

\begin{tabular}{ccccc}
\hline Wave number & Wave amplitude $(\mathbf{m m})$ & Material & Cell size $(\mathbf{m m})$ & Wall thickness $(\mathbf{m m})$ \\
\hline 0 & 0.06 & Aluminium & 3.175 & 0.0254 \\
1 & 0.09 & Nomex & 3.96875 & 0.0381 \\
2 & 0.12 & Carbon fiber & 4.7625 & 0.0508 \\
3 & 0.15 & Glass fiber & 6.35 & 0.0635 \\
\hline
\end{tabular}

Coding was performed using the expressions in Table 3, respectively, for various design cases. N, A, M, C, and T are the wave number, wave amplitude, material, cell size, and wall thickness in the Na-Ab-Mc-Cd-Te code, respectively. Moreover, their values are the letters a, b, c, d, and e. For example, N2-A3-M2-C4-T1 implies that the wave number is 2, the wave amplitude is $0.12 \mathrm{~mm}$, the material is Nomex ${ }^{\circledR}$, the cell size is $6.35 \mathrm{~mm}$ and the wall thickness is $0.0254 \mathrm{~mm}$.

\subsection{Effect of wave number}

The wave number of the wavy honeycomb influences compression performance (San Ha et al., 2019, Yang et al., 2018). For this reason, the effect of the wave number on IPCF and SEA was examined in this section. The wave numbers used are shown in Figure 7.

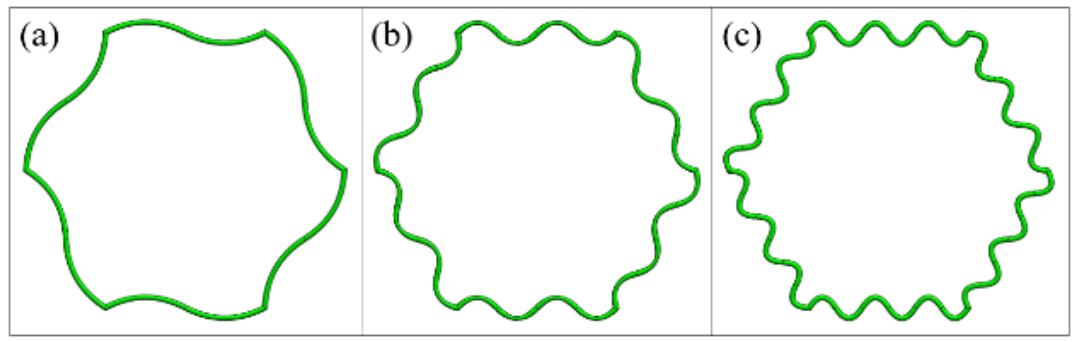

Figure 7 (a) One wave, (b) two waves, (c) three waves.

The material, cell size, and wall thickness of all simulated wavy honeycombs are the same in this section. These parameters are respectively Nomex ${ }^{\circledR}, 6.35 \mathrm{~mm}$, and $0.0254 \mathrm{~mm}$. Additionally, three wave numbers were used. The effect of the wave number on the IPCF and SEA is shown in Figure 8.
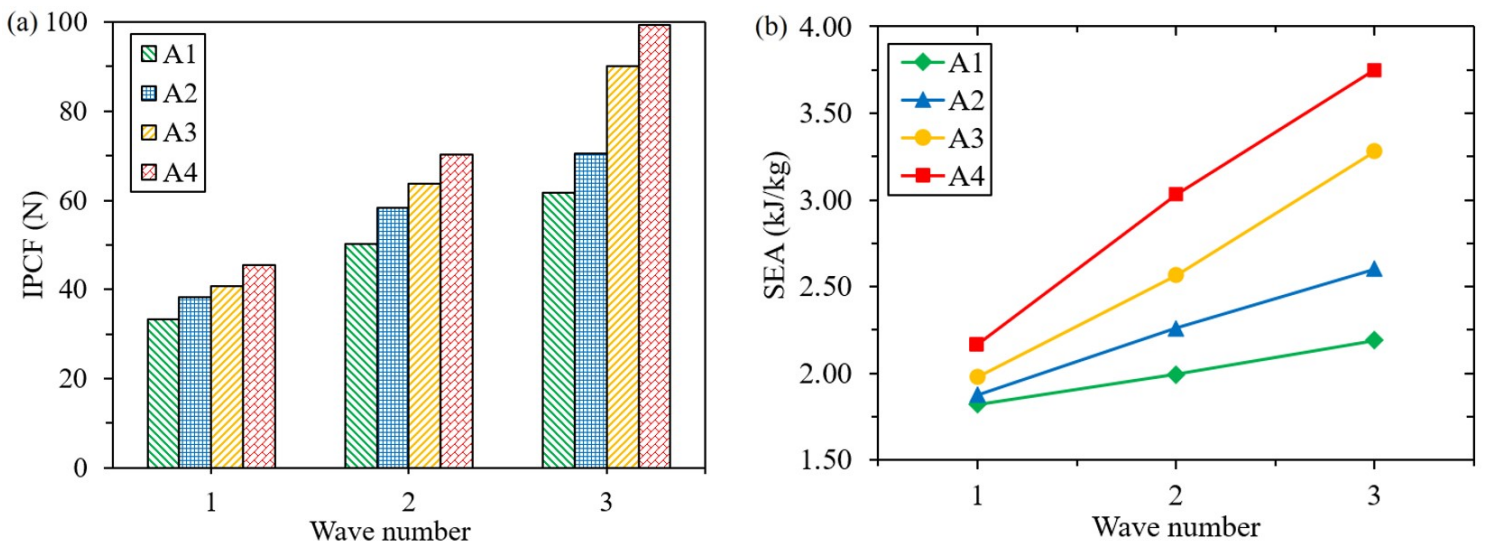

Figure 8 Effect of wave number on (a) IPCF and (b) SEA.

For the wave amplitudes of A1 and A2, IPCF increases by $84.81 \%$ and $84.72 \%$, respectively, when the wave number increases from one to three. Moreover, for A3 and A4 wave amplitudes, IPCF increases at the greater rate of $121.59 \%$ and $118.76 \%$, respectively. When the wave number rises from one to three for the A1 and A2 wave amplitudes, SEA ascends slowly by $20.23 \%$ and $38.87 \%$, respectively. Furthermore, for A3 and A4 wave amplitudes, the SEA rises rapidly by $65.73 \%$ and $75.08 \%$ respectively. 


\subsection{Effect of wave amplitude}

The wave amplitude of the wavy honeycomb impacts the compression performance (San Ha et al., 2019, Yang et al., 2018). For this reason, the effect of wave amplitude on IPCF and SEA was examined in this section. In Figure 9, the varied wave amplitudes used are shown.

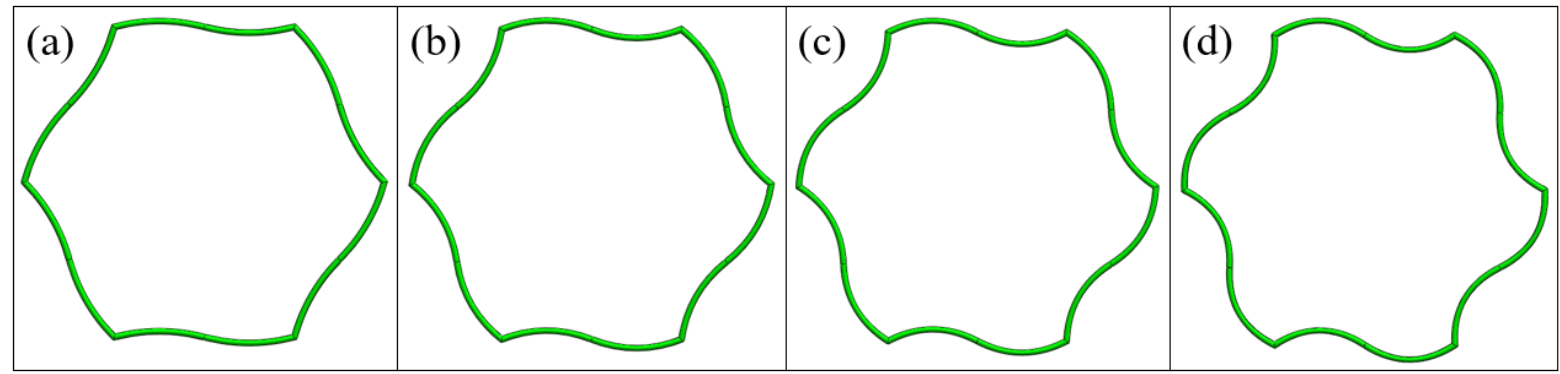

Figure 9 (a) $0.06 \mathrm{~mm}$, (b) $0.09 \mathrm{~mm},(c) 0.12 \mathrm{~mm}$, (d) $0.15 \mathrm{~mm}$

The material, cell size, and wall thickness of all simulated wavy honeycombs are the same in this section. These parameters are respectively Nomex ${ }^{\circledR}, 6.35 \mathrm{~mm}$, and $0.0254 \mathrm{~mm}$. Also, four wave amplitudes were used. The effect of the wave number on the IPCF and SEA is shown in Figure 10.
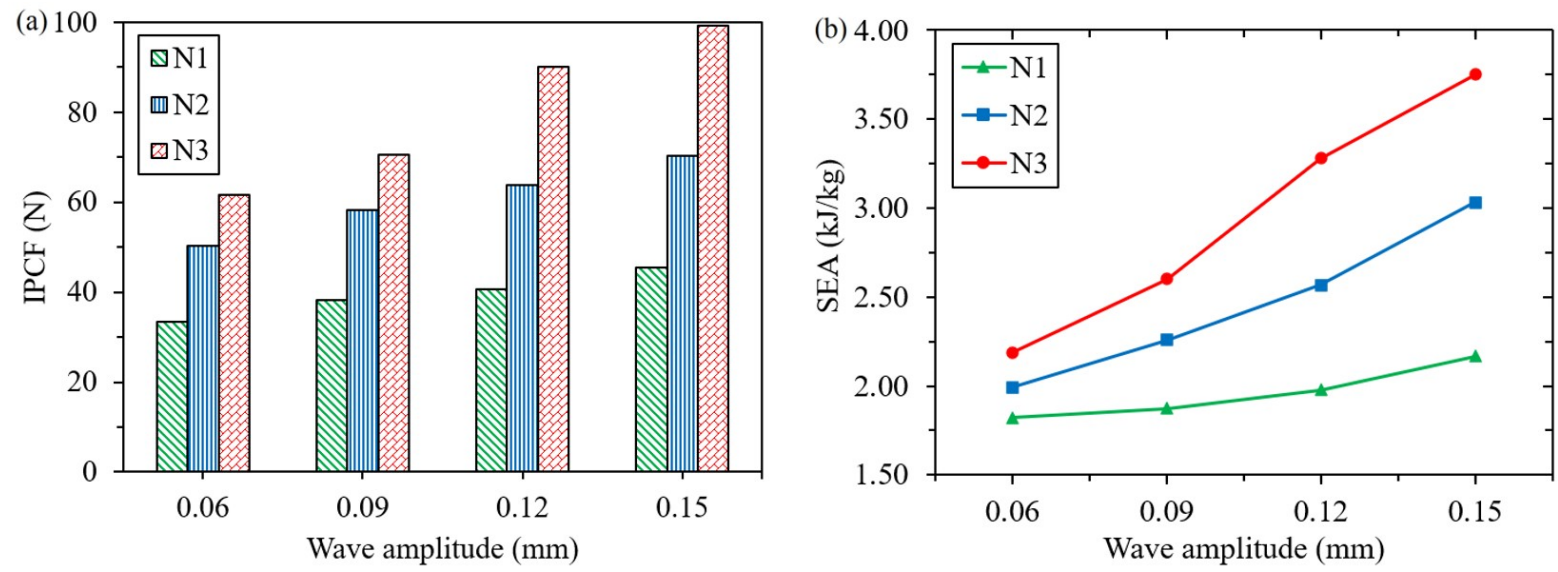

Figure 10 Effect of wave amplitude on (a) IPCF and (b) SEA.

For N1, N2, and N3 wave numbers, the IPCF increases by $35.92 \%, 40.13 \%$, and $60.89 \%$, respectively, when the wave amplitude goes up from $0.06 \mathrm{~mm}$ to $0.15 \mathrm{~mm}$. For the $\mathrm{N} 1$ wave number, the SEA rises by $18.99 \%$ when the wave amplitude ascends from $0.06 \mathrm{~mm}$ to $0.15 \mathrm{~mm}$. In addition, SEA rises rapidly by $52.19 \%$ and $71.3 \%$ respectively for the $\mathrm{N} 2$ and N3 wave numbers.

\subsection{Effect of material}

The material of the wavy honeycomb influences the performance of compression (Heimbs, 2009). For this reason, the effect of the material on IPCF and SEA was examined in this section. Three wavy honeycombs (N1A1, N2A2, and N3A3) and four materials (aluminum, Nomex ${ }^{\circledR}$, carbon fiber, and fiberglass) were considered for this purpose. Moreover, other design parameters are $6.35 \mathrm{~mm}$ and $0.0254 \mathrm{~mm}$, respectively (cell size and wall thickness). For three wavy honeycombs, these values are the same. The material's effect on IPCF and SEA is shown in Figure 11. 

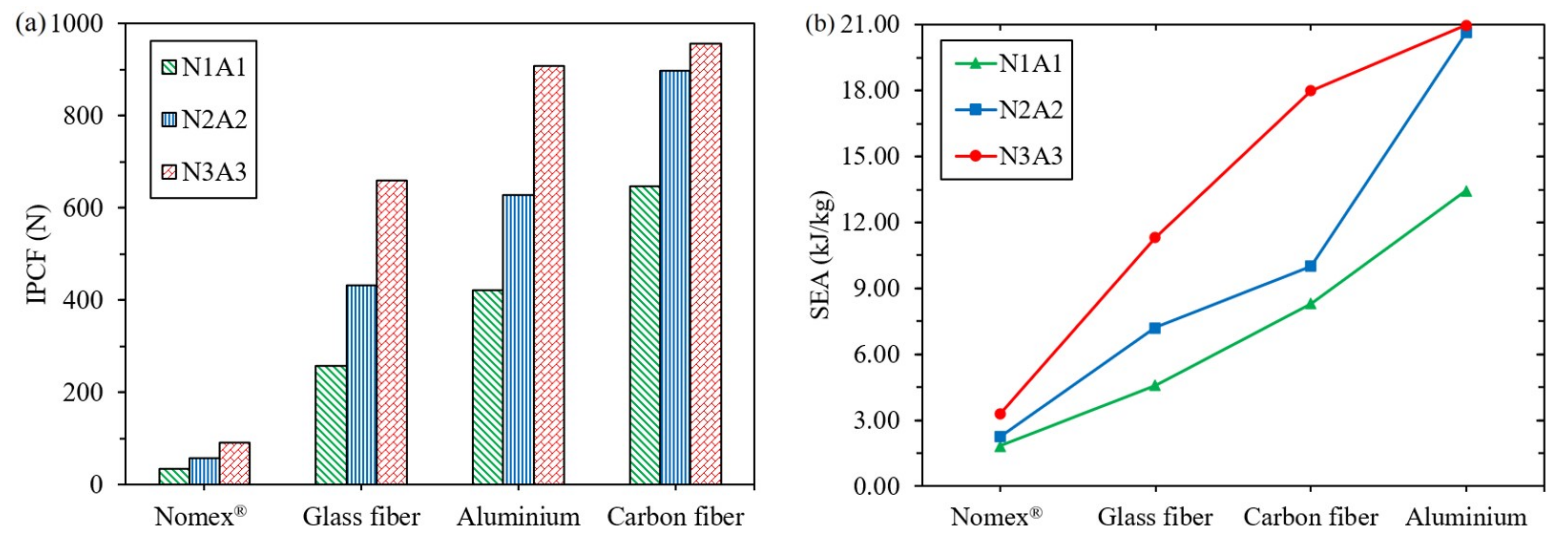

Figure 11 Effect of material on (a) IPCF and (b) SEA.

The IPCF of carbon fiber is the highest. Furthermore, aluminum has the highest SEA. However, the two values of Nomex ${ }^{\circledR}$ are the lowest. Additionally, as the number of waves and wave amplitude increase, these values also increase. However, when these carbon fiber parameters rise (from N2A2 to N3A3), IPCF ascends slowly by $5.51 \%$. This slow rise is also similar to the upward trend of aluminum SEA, for which the rate of increase is $16.48 \%$.

\subsection{Effect of cell size}

Compression performance is affected by the cell size of the wavy honeycomb (Meran et al., 2014). For this reason, the effect of cell size on IPCF and SEA was examined in this section. Three wavy honeycombs (N1A1, N2A2, and N3A3) and four cell sizes $(3.175 \mathrm{~mm}, 3.96875 \mathrm{~mm}, 4.7625 \mathrm{~mm}$, and $6.35 \mathrm{~mm}$ ) were considered for this purpose. Furthermore, Nomex $^{\circledR}$ and $0.0254 \mathrm{~mm}$ respectively are the other design parameters (material and wall thickness). For three wavy honeycombs, these values are the same. The material's effect on IPCF and SEA is shown in Figure 12.
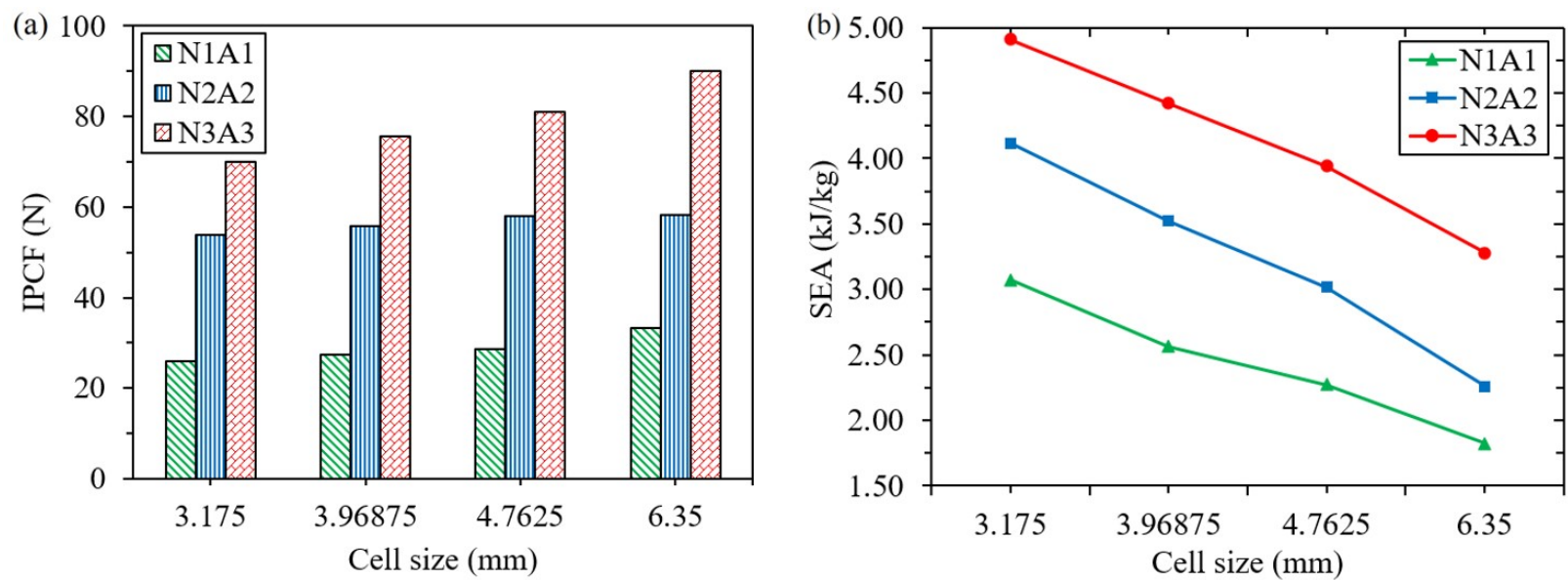

Figure 12 Effect of cell size on (a) IPCF and (b) SEA.

For N2A2, the IPCF increases by $8.18 \%$ when the cell size rises from $3.175 \mathrm{~mm}$ to $6.35 \mathrm{~mm}$. In addition, IPCF rapidly ascends by $28.95 \%$ and $28.65 \%$ for N1A1 and N3A3, respectively. There is a gradual decrease in SEA as the cell size increases, contrary to the IPCF.

\subsection{Effect of wall thickness}

Compression performance is affected by the wall thickness of the wavy honeycomb (Meran et al., 2014, San Ha et al., 2019, Yang et al., 2018). For this reason, the impact of wall thickness on IPCF and SEA was examined in this section. Three wavy honeycombs (N1A1, N2A2, and N3A3) and four wall thicknesses $(0.0254 \mathrm{~mm}, 0.0381 \mathrm{~mm}, 0.0508$ $\mathrm{mm}$, and $0.0635 \mathrm{~mm}$ ) were taken into consideration for this purpose. In addition, Nomex ${ }^{\circledR}$ and $6.35 \mathrm{~mm}$ respectively are the other design parameters (material and cell size). For the three wavy honeycombs, these values are the same. The impact of wall thickness on IPCF and SEA can be seen in Figure 13. 

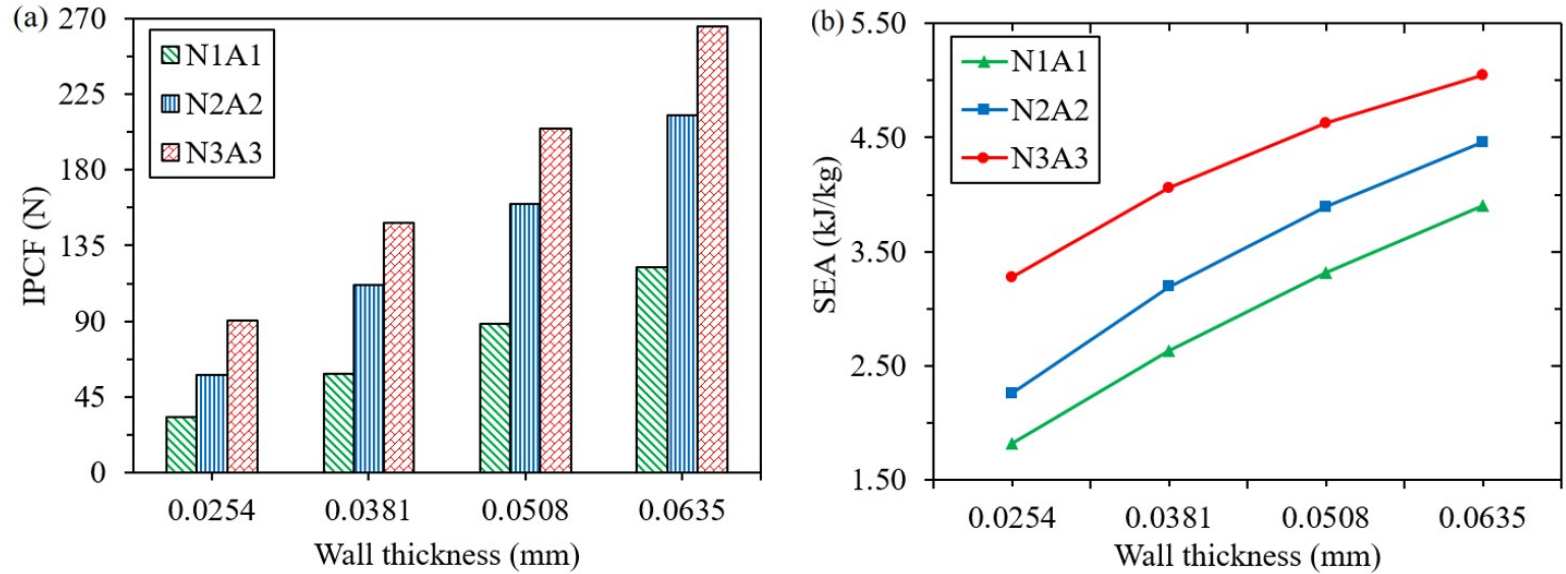

Figure 13 Effect of wall thickness on (a) IPCF and (b) SEA.

In a similar trend, as the wall thickness increases, IPCF and SEA also rise. For wavy honeycombs with high wave number and wave amplitude, IPCF also rises more.

\section{ESTIMATION OF COMPRESSION PERFORMANCE BY DECISION TREE ALGORITHM}

In this section, a decision tree algorithm was proposed for wavy honeycombs. The data set for the estimation model created using the decision tree needs to be defined. To obtain the data, the full factorial basis (Antony, 2014, Hu et al., 2020) was taken from designs of experimental (DOE) methods. For this strategy, combinations of all design parameters were created. In this way, it is possible to examine the effect of design parameters on the results (IPCF and EA). To create these combinations, the design parameters in Table 3 were used. Wavy honeycombs have five design parameters, whereas, because there are no waves, regular honeycombs have three design parameters. The data set was, therefore, divided into two and shown in Figure 14.

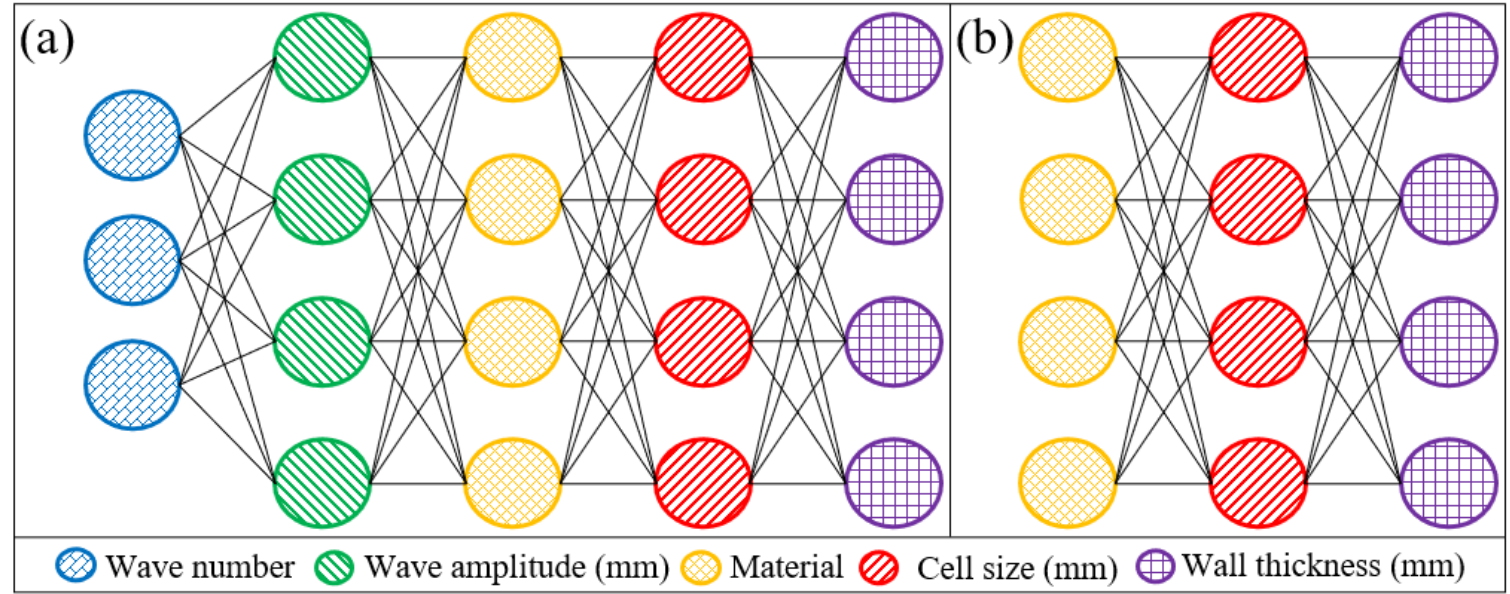

Figure 14 Full factorial for (a) wavy honeycombs and (b) hexagonal honeycombs.

According to Figure 14 , there are 832 combinations in total, $768(3 \times 4 \times 4 \times 4 \times 4)$ for wavy honeycombs and 64 ( $4 \times 4 \times 4)$ for hexagonal honeycombs. Figure 15a shows the IPCF of the four materials, and Figure 15b shows the detailed results for Nomex ${ }^{\circledR}$. 

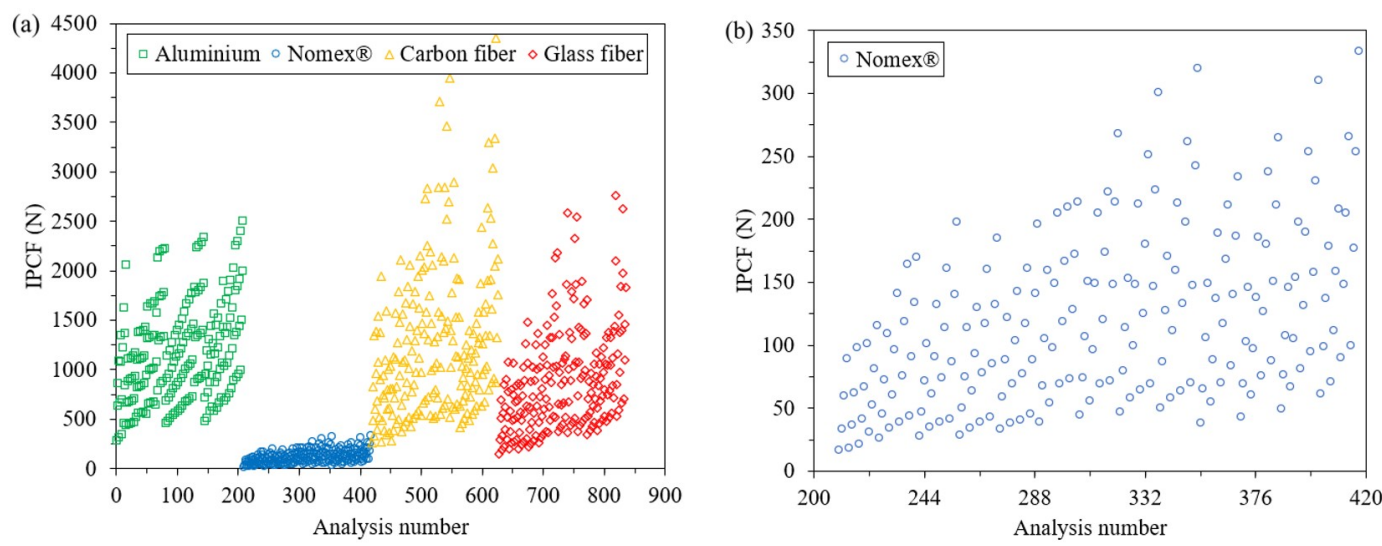

Figure 15 IPCF results of (a) four materials and (b) Nomex ${ }^{\circledR}$.

Carbon fiber values are higher in general distribution than other materials. Furthermore, the values are close to each other for aluminum and glass fiber. On the other hand, the values for Nomex ${ }^{\circledR}$ are the lowest. Figure 16a shows the EA of the four materials, and Figure $16 \mathrm{~b}$ shows the detailed results for Nomex ${ }^{\circledR}$.
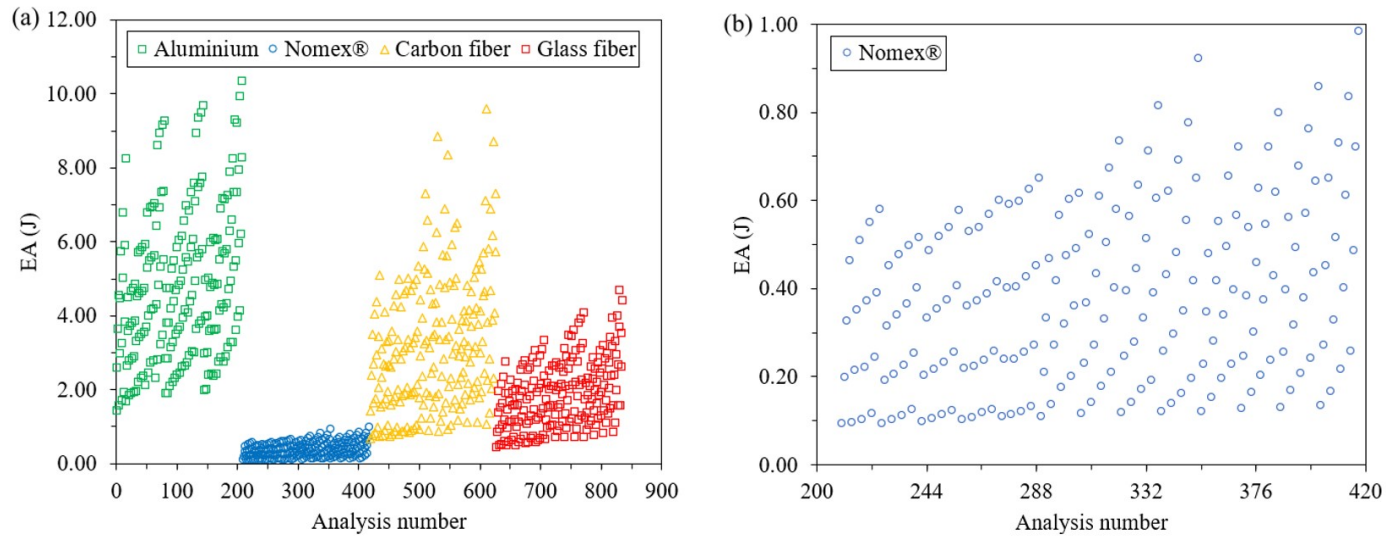

Figure 16 EA results of (a) four materials and (b) Nomex ${ }^{\circledast}$

Aluminum has the highest EA. The highest values, after that, belong to carbon fiber and glass fiber, respectively. In Figure 17, the relationship between design parameters and results (IPCF and EA) can be seen.
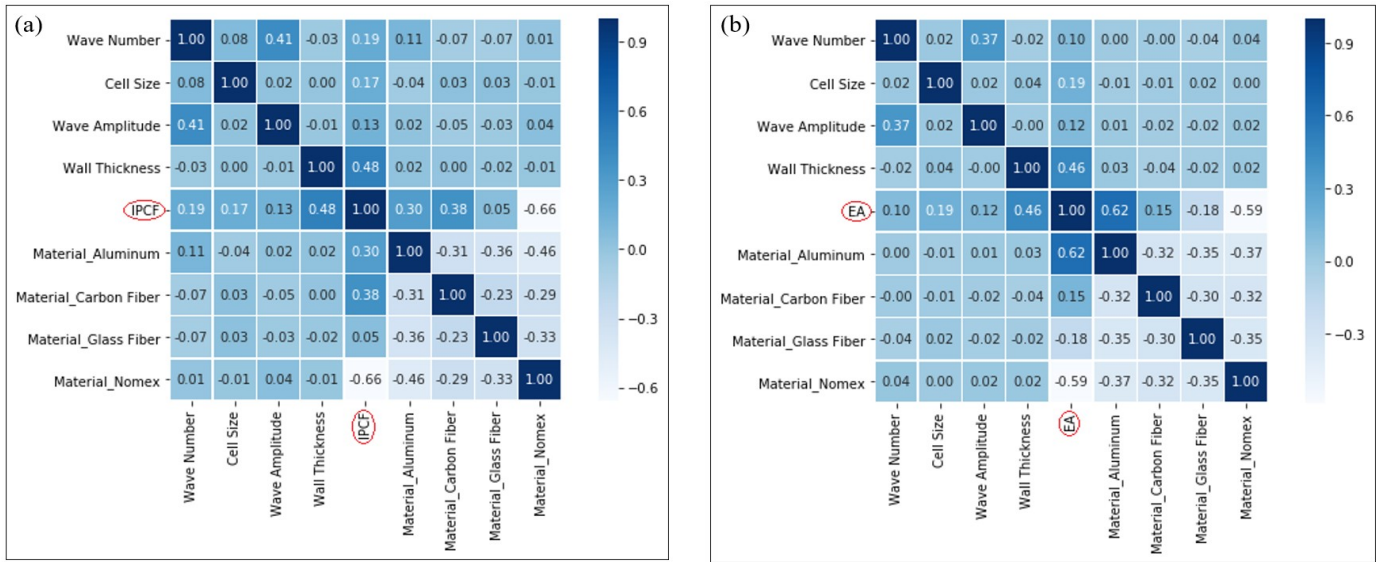

Figure 17 Correlation of design parameters for (a) IPCF and (b) EA.

The coefficients vary between 1 and -1 . If the value is 1 , the parameters have a strong linear relationship between them. However, a strong inverse ratio exists if the value is -1 . There is no relationship if the value is 0 , meaning that the two variables do not affect each other. 
The parameters that have the most impact on IPCF are wall thickness and carbon fiber, while Nomex ${ }^{\circledR}$ and glass fiber have the least impact. There is a strong relationship between wave number and wave amplitude. On the other hand, the relationship between wave parameter and material parameter is close to 0 .

EA is strongly affected by aluminum and wall thickness. The effect of Nomex ${ }^{\circledR}$ and glass fiber is the least, similar to the IPCF correlation figure. Figure 18 shows the flowchart for the decision tree algorithm developed using Python.

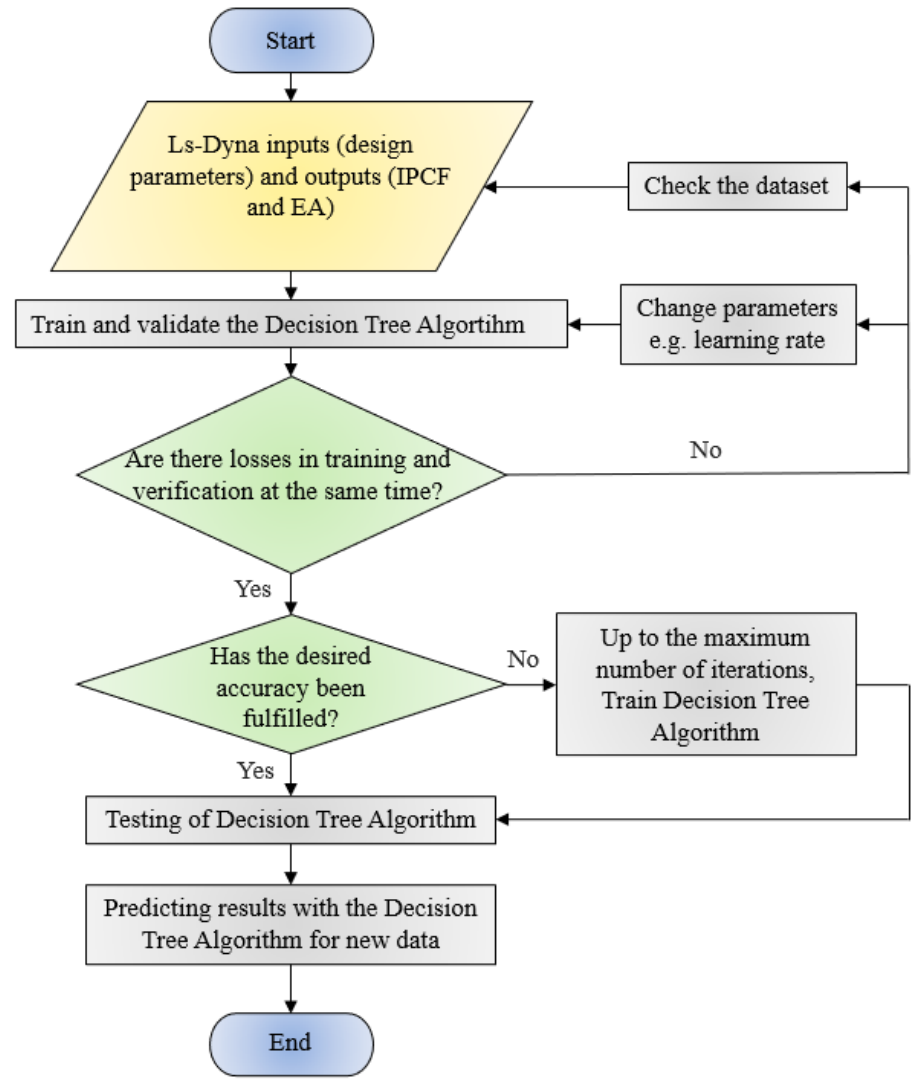

Figure 18 Flow chart for the decision tree algorithm.

First, design parameters (inputs) and analysis results (outputs) are defined according to this flow chart. Using $30 \%$ of the data, the algorithm is trained and verification is performed using $70 \%$. At the next stage, it is decided whether training and verification losses are present at the same time. The learning rate and depth of the decision tree algorithm are altered if the answer is no, and the data set is checked. It is decided after this stage whether the desired accuracy is already attained. With Ls-Dyna, 11 analyses that are not defined in the algorithm were first solved, and then the results were estimated with the estimation model. Table 4 show the design parameters, results (IPCF and EA), estimative values, and error rates for the new data.

Table 4 Estimated values and error rates (\%) for the new data of IPCF and EA.

\begin{tabular}{|c|c|c|c|c|c|c|c|c|c|c|c|}
\hline No & $\mathbf{N}$ & A & M & C & $T$ & Result (IPCF) & Estimate (IPCF) & Error for IPCF (\%) & Result (EA) & Estimate (EA) & Error for EA (\%) \\
\hline 1 & 2 & 0.07 & Nomex $^{\circledR}$ & 4.5 & 0.036 & 80.65 & 80 & 0.81 & 0.24 & 0.25 & 2.3 \\
\hline 2 & 3 & 0.07 & G. Fiber & 5.5 & 0.036 & 855 & 751 & 12.12 & 1.49 & 1.43 & 3.91 \\
\hline 3 & 3 & 0.1 & C. Fiber & 4.5 & 0.06 & 3222 & 3040 & 5.64 & 6.6 & 5.66 & 14.2 \\
\hline 4 & 2 & 0.1 & Nomex $^{\circledR}$ & 3.5 & 0.052 & 165 & 149 & 9.44 & 0.46 & 0.42 & 8.82 \\
\hline 5 & 1 & 0.07 & C. Fiber & 3.5 & 0.052 & 969 & 827 & 14.65 & 2.7 & 2.7 & 0.17 \\
\hline 6 & 2 & 0.1 & Aluminum & 3.5 & 0.06 & 1250 & 1190 & 4.8 & 5.18 & 4.73 & 8.64 \\
\hline 7 & 2 & 0.13 & Aluminum & 5.5 & 0.036 & 1130 & 1060 & 6.19 & 4.7 & 4.39 & 6.55 \\
\hline 8 & 1 & 0.13 & C. Fiber & 4.5 & 0.036 & 795 & 873 & 9.81 & 1.71 & 1.9 & 10.94 \\
\hline 9 & 1 & 0.1 & G. Fiber & 3.5 & 0.052 & 813 & 741 & 8.81 & 1.85 & 1.69 & 8.73 \\
\hline 10 & 1 & 0.07 & Nomex $^{\circledR}$ & 3.5 & 0.06 & 112 & 101 & 9.82 & 0.44 & 0.47 & 7.38 \\
\hline 11 & 3 & 0.13 & Aluminum & 5.5 & 0.052 & 1770 & 1520 & 14.12 & 7.34 & 6.3 & 14.21 \\
\hline
\end{tabular}


Error rates for IPCF vary between $0.81 \%$ and $14.65 \%$, according to Table 4 . Additionally, EA error rates range from $0.17 \%$ to $14.21 \%$, according to Table 4 . When the algorithm is trained with more data, these error rates can be reduced.

\section{CONCLUSIONS}

In this study, the effect of design parameters (wave number, wave amplitude, material, cell size, and cell wall thickness) on compression performance was investigated. In addition, performance values were estimated using a machine learning algorithm. First, hexagonal honeycomb models were designed using Ls-Dyna. The experimental compression test results of aluminum and Nomex ${ }^{\circledR}$ were used to verify these models. When the experimental and numerical results were compared, it was seen that the stress-strain curves were quite compatible, and the deformation shapes were similar. This showed that the models can be used for wavy honeycombs. To examine the effect of design parameters on mechanical performance, several analyses were conducted. Analysis results show that wavy honeycombs are better than hexagonal honeycombs in terms of compression performance. Accordingly, when the wave number is 3 , the IPCF and SEA values increase by $121.59 \%$ and $75.08 \%$, respectively, for honeycombs with the same geometric properties. Furthermore, when the wave amplitude is $0.15 \mathrm{~mm}$, IPCF and SEA rise by $60.89 \%$ and $71.3 \%$, respectively. Considering the material effect, carbon fiber may be preferred for designs where strength is essential, and aluminum for areas where energy absorption is important. Using the full factorial method, 832 different cases were created. The estimation algorithm for wavy honeycombs was proposed in this study. The design parameters and mechanical performance of these analyses were used in the training and validation of the decision tree algorithm. IPCF and EA were estimated at low error rates ranging from $0.17 \%$ to $14.65 \%$. Through the decision tree algorithm, the results of the LsDyna analysis can be estimated in a shorter time using a smaller central processing unit (CPU). As a result, the feasibility of machine learning for wavy honeycombs was proven by this study. This methodology could be used for sandwich structure performance in future studies.

\section{Acknowledgment}

This research did not receive any specific grant from funding agencies in the public, commercial, or nonprofit sectors. The authors would like to thank data scientist Orhan Solak for his contribution to the work of machine learning.

Author's Contributions: Conceptualization, B Aşçıŏlu Temiztaş; Methodology, B Aşçığlu Temiztaş; Investigation, B Bolat; Writing - original draft, A Solak; Writing - review \& editing, A Solak; Resources, A Solak, B Aşçığlu Temiztaş, B Bolat; Supervision, B Aşçığlu Temiztaş, B Bolat.

Editor: Marcílio Alves.

\section{References}

Antony, J. (2014). Design of experiments for engineers and scientists. Elsevier.

Bitzer, T. N. (1997). Honeycomb technology: materials, design, manufacturing, applications and testing. Springer Science \& Business Media.

Foo, C. C., Chai, G. B., \& Seah, L. K. (2007). Mechanical properties of Nomex material and Nomex honeycomb structure. Composite structures, 80(4), 588-594.

García, Á., Anjos, O., Iglesias, C., Pereira, H., Martínez, J., \& Taboada, J. (2015). Prediction of mechanical strength of cork under compression using machine learning techniques. Materials \& Design, 82, 304-311.

He, Q., Feng, J., Chen, Y., \& Zhou, H. (2020). Mechanical properties of spider-web hierarchical honeycombs subjected to outof-plane impact loading. Journal of Sandwich Structures \& Materials, 22(3), 771-796.

Heimbs, S. (2008). Sandwichstrukturen mit Wabenkern: Experimentelle und numerische Analyse des Schädigungsverhaltens unter statischer und kurzzeitdynamischer Belastung.

Heimbs, S. (2009). Virtual testing of sandwich core structures using dynamic finite element simulations. Computational Materials Science, 45(2), 205-216. 
Hou, K. W., Yang, J. L., Liu, H., \& Sun, Y. X. (2015). Energy absorption behavior of metallic staggered double-sine-wave tubes under axial crushing. Journal of Mechanical Science and Technology, 29(6), 2439-2449.

Hu, Z., Qin, X., Li, Y., \& Ni, M. (2020). Welding parameters prediction for arbitrary layer height in robotic wire and arc additive manufacturing. Journal of Mechanical Science \& Technology, 34(4).

Jiang, H., Ren, Y., Jin, Q., Zhu, G., Hu, Y., \& Cheng, F. (2020). Crashworthiness of novel concentric auxetic reentrant honeycomb with negative Poisson's ratio biologically inspired by coconut palm. Thin-Walled Structures, 154, 106911.

Khan, M. K., Baig, T., \& Mirza, S. (2012). Experimental investigation of in-plane and out-of-plane crushing of aluminum honeycomb. Materials Science and Engineering: A, 539, 135-142.

Maimon, O. Z., \& Rokach, L. (2014). Data mining with decision trees: theory and applications (Vol. 81). World scientific.

Meran, A. P., Toprak, T., \& Muğan, A. (2014). Numerical and experimental study of crashworthiness parameters of honeycomb structures. Thin-Walled Structures, 78, 87-94.

Qi, Z., Zhang, N., Liu, Y., \& Chen, W. (2019). Prediction of mechanical properties of carbon fiber based on cross-scale FEM and machine learning. Composite Structures, 212, 199-206.

Roy, R., Park, S. J., Kweon, J. H., \& Choi, J. H. (2014). Characterization of Nomex honeycomb core constituent material mechanical properties. Composite Structures, 117, 255-266.

San Ha, N., Lu, G., \& Xiang, X. (2019). Energy absorption of a bio-inspired honeycomb sandwich panel. Journal of materials science, 54(8), 6286-6300.

Seemann, R. A. L. F., \& Krause, D. I. E. T. E. R. (2014, July). Numerical modelling of nomex honeycomb cores for detailed analyses of sandwich panel joints. In 11th World Congress on Computational Mechanics (WCCM XI).

Seemann, R., \& Krause, D. (2017). Numerical modelling of Nomex honeycomb sandwich cores at meso-scale level. Composite Structures, 159, 702-718.

Soutis, C., Mohamed, G., \& Hodzic, A. (2011). Modelling the structural response of GLARE panels to blast load. Composite Structures, 94(1), 267-276.

Wagner, H. N. R., Köke, H., Dähne, S., Niemann, S., Hühne, C., \& Khakimova, R. (2019). Decision tree-based machine learning to optimize the laminate stacking of composite cylinders for maximum buckling load and minimum imperfection sensitivity. Composite Structures, 220, 45-63.

Yang, X., Sun, Y., Yang, J., \& Pan, Q. (2018). Out-of-plane crashworthiness analysis of bio-inspired aluminum honeycomb patterned with horseshoe mesostructure. Thin-Walled Structures, 125, 1-11.

Zhang, W., Yin, S., Yu, T. X., \& Xu, J. (2019). Crushing resistance and energy absorption of pomelo peel inspired hierarchical honeycomb. International Journal of Impact Engineering, 125, 163-172.

Zhang, Y., Lu, M., Wang, C. H., Sun, G., \& Li, G. (2016). Out-of-plane crashworthiness of bio-inspired self-similar regular hierarchical honeycombs. Composite Structures, 144, 1-13.

Zhang, Y., Sun, G., Xu, X., Li, G., Huang, X., Shen, J., \& Li, Q. (2013). Identification of material parameters for aluminum foam at high strain rate. Computational Materials Science, $74,65-74$.

Zhou, Y., Sun, Y., \& Huang, T. (2020). Bird-strike resistance of composite laminates with different materials. Materials, $13(1), 129$. 